\title{
Deglutition Impairment during Dual Task in Parkinson Disease Is Associated with Cognitive Status
}

\author{
${ }^{1}$ Department of Speech Therapy, Universidade de Passo Fundo, Passo \\ Fundo, Brazil \\ 2 Program of Graduate Studies in Medical Sciences, Universidade \\ Federal do Rio Grande do Sul, Cesar Lombroso, Porto Alegre, Brazil \\ ${ }^{3}$ Departament of Health and Human Communication, Speech- \\ Language Pathology Course, Universidade Federal do Rio Grande do \\ Sul, Porto Alegre, Rio Grande do Sul, Brazil \\ ${ }^{4}$ Department of Developmental Psychology and Personality Ramiro \\ Barcelos, Universidade Federal do Rio Grande do Sul, Porto Alegre, \\ Rio Grande do Sul, Brazil \\ ${ }^{5}$ Department of Neurology, Universidade Federal de Ciências da \\ Saúde de Porto Alegre, Porto Alegre, Brazil \\ ${ }^{6}$ Department of Neurology, Distúrbios do Movimento, Hospital de \\ Clínicas de Porto Alegre, Porto Alegre, Brazil
}

Luciana Grolli Ardenghi ${ }^{1 \odot}$ Alana Verza Signorini ${ }^{2}$ Gerson Schulz Maahs ${ }^{3}$ Fabio Selaimen ${ }^{2}$

Konrado Massing Deutsch ${ }^{3}$ Silvia Dornelles ${ }^{4}$ Carlos Roberto de Mello Rieder ${ }^{5,6}$ Address for correspondence Luciana Grolli Ardenghi, PhD, Departmento de Fonoaudiologia, Universidade de Passo Fundo, Campus II, Passo Fundo, 99052-900, Brazil (e-mail: lucianaardenghi@yahoo.com.br).

Int Arch Otorhinolaryngol 2021;25(1):e41-e47.

\begin{abstract}
Keywords

- deglutition disorders

- Parkinson disease

- endoscopy

- cognition

Introduction Dysphagia is a relevant symptom in Parkinson disease (PD), and its pathophysiology is poorly understood. To date, researchers have not investigated the effects of combined motor tasks on swallowing. Such an assessment is of particular interest in PD, in which patients have specific difficulties while performing two movements simultaneously.

Objective The present study tested the hypothesis that performing concurrent tasks could decrease the safety of swallowing in PD patients as visualized using fiberoptic endoscopic evaluation of swallowing (FEES).

Methods A total of 19 patients and 19 controls matched by age, gender, and level of schooling were compared by FEES under two conditions: isolated swallowing and dual task (swallowing during non-sequential opposition of the thumb against the other fingers). The two tasks involved volumes of food of $3 \mathrm{~mL}$ and $5 \mathrm{~mL}$. The PD subjects were classified according to the Hoehn \& Yahr (H\&Y) Scale, the Mini Mental State Examination (MMSE), and the Montreal Cognitive Assessment (MoCA). The FEES assessment was performed according to the Boston Residue and Clearance Scale (BRACS).

Results The data showed a significant worsening of swallowing in the dual task assessment for both volumes ( $3 \mathrm{~mL}: p \leq 0.001 ; 5 \mathrm{~mL}: p \leq 0.001$ ) in the PD group. A correlation between the MoCA and dual-task swallowing of $3 \mathrm{~mL}$ was also found.

Conclusion These findings suggest that additional tasks involving manual motor movements result in swallowing impairment in patients with PD. Moreover, these data highlight the need to further evaluate such conditions during treatment and assessment of PD patients.
\end{abstract}

received

May 18, 2018

accepted

October 26, 2019

published online

April 24, 2020
DOI https://doi.org/

10.1055/s-0039-3402440.

ISSN 1809-9777. (c) 2020. Fundação Otorrinolaringologia. All rights reserved.

This is an open access article published by Thieme under the terms of the Creative Commons Attribution-NonDerivative-NonCommercial-License, permitting copying and reproduction so long as the original work is given appropriate credit. Contents may not be used for commercial purposes, or adapted, remixed, transformed or built upon. (https://creativecommons.org/ licenses/by-nc-nd/4.0/)

Thieme Revinter Publicações Ltda., Rua do Matoso 170, Rio de Janeiro, RJ, CEP 20270-135, Brazil 


\section{Introduction}

Dysphagia can significantly affect the quality of life of people with Parkinson disease (PD); it is a risk factor for aspiration pneumonia, the leading cause of death in patients with PD. ${ }^{1-3}$ Dysphagia is very common in PD, affecting over $70 \%$ of patients. ${ }^{4}$ The specific swallowing difficulties most frequently associated with PD are found in the oral and pharyngeal phases, resulting in abnormal bolus formation, delayed swallowing reflex, and prolonging pharyngeal transit time. ${ }^{5}$

Deglutition disorders generally require good care, and can lead to dehydration and malnutrition in patients with $\mathrm{PD},{ }^{6,7}$ in addition to aspiration syndromes. Gastrointestinal symptoms are common even before the onset of PD motor symptoms, even though patients recognize their difficulties later. ${ }^{8}$ Parkinson disease can affect any phase of the swallowing process (preoral, oral, pharyngeal, or esophageal), as well as the adjacent respiratory, olfactory, and salivary systems, due to slowed movement execution, restricted range of motion, reduced physical strength, and, most likely, impaired perception. ${ }^{9}$ Oropharyngeal dysfunction can occur during the early stages of the disease, and is characterized by repetitive swallowing (double or triple) for a single bolus, due to esophageal peristalsis deficits. ${ }^{10}$ It is plausible that dysphagia can remain subclinical or asymptomatic as patients gradually adapt to it as a consequence of the slow progression of PD. ${ }^{11}$ The loss of somatosensory input leads to silent aspiration attributable to the accumulation of non-identifiable residues in the oropharyngeal region. ${ }^{12}$

The fiber optic endoscopic evaluation of swallowing (FEES) is considered the gold standard test for the diagnosis and management of swallowing disorders, minimizing the risk of aspiration. ${ }^{13}$ This test involves fiber optic examination of the pharynx and larynx, the swallowing of various food substances under endoscopic visualization, and the response to therapeutic maneuvers. ${ }^{14}$

Tasks that require simultaneous performance of two or more functions (walking and talking on the phone, or walking while repeating a shopping list, for example) may be particularly difficult for patients with PD. Specific cognitive aspects, such as subdividing or alternating attention, have been specifically associated with impairment to perform two tasks simultaneously. Studies on simultaneous tasks involving locomotion are more common in the literature, and their main objective is to understand and prevent falls in patients with PD. ${ }^{15,16}$ Evidence suggests that patients, while in locomotion, should focus their attention on the act of walking, thinking about each step and reducing automation in their movements while discontinuing simultaneous tasks. ${ }^{17}$

However, few studies have highlighted the effect of dual tasks on swallowing. ${ }^{18,19}$ A study ${ }^{18}$ that analyzed swallowing of $10 \mathrm{~mL}$ of a liquid viewed through video fluoroscopy concurrently with the memorization of numbers showed that both tasks were impaired when they were performed simultaneously. In other words, swallowing was impaired when it was performed along with a cognitive task. Despite cognitivemotor interference, the patients with greater impairments regarding cognition and attention demonstrated improved swallowing safety under a dual-task condition.
A comprehensive understanding of the mechanisms that influence deglutition under dual-task conditions is important to address concerns regarding feeding safety. The act of swallowing occurs in a social environment with motor competition, such as movement of the hand and arm to take food to the oral cavity, for example. The present study tested the hypothesis that performing concurrent tasks could decrease the safety of swallowing in PD patients as visualized using the FEES.

\section{Methods}

The present study was approved by the Ethics in Research Committee (approval under number 1.008.61) of our institution.

\section{Participants}

The present is an interventional, case-control study, and it was conducted by dividing the subjects into two groups. One group included patients with PD. The group composed of healthy controls (HCs) included individuals who were matched for chronological age, gender, and level of schooling.

A significance level of $5 \%$, power of $90 \%$, and a standardized effect size of one standard deviation in the results of the 2 evaluations (isolated and double task) were used to assess correlations in at least 13 individuals in each group. The calculation was performed using the freeware package WinPepi, version 11.43, and was based on the study by Brodsky et al. ${ }^{19}$ The survey sample was expanded to 19 PD patients and 19 HCs.

The PD patients were sorted at the Parkinson clinic of the reference hospital in Brazil. All evaluations were performed while the patients were receiving antiparkinsonian drugs and during the "on" phase.

Visitors to the otorhinolaryngology ward were included in the control group. These individuals were matched for gender, chronological age (considering \pm 4 years), and level of schooling (considering 5 years of schooling as the cut-off).

\section{Inclusion and Exclusion Criteria}

The patients who met the following criteria were included in the PD group: 1) willingness and ability to provide informed consent to participate in the study; 2) previously-confirmed diagnosis of PD; 3 ) no self-reported history of swallowing difficulty; 4) absence of motor impairments that could prevent manual tasks; 5) presence of the hand movement skills necessary for the study; 6) absence of any malformation and/or surgery involving significant resection of tissues or the laryngeal structure or reconstruction of the larynx; 7) absence of any disease causing stunting of the esophagus and of the esophageal surgery tract; and 8) no reconstruction surgery of the esophagus and/or any associated neurological disorders.

For the HCs, the inclusion criteria were the same except for the diagnosis of PD.

\section{Scales and Procedures}

The patients with PD were classified by a neurologist according to the Hoehn \&Yahr (H\&Y) Scale, ${ }^{20}$ which classifies PD in terms of the degree of severity of the symptoms. All subjects included in the study underwent a brief cognitive assessment 
by an expert using the Mini Mental State Examination $(\mathrm{MMSE})^{21}$ and the Montreal Cognitive Assessment (MoCA). ${ }^{22}$

Fiber Optic Endoscopic Evaluation of Swallowing (FEES) Experimental procedures for dual tasks were performed in the hospital using video nasoendoscopy. The FEES examination was performed using the protocol described by Langmore et al. ${ }^{23}$ The characteristics of the apparatus used for fiber optic nasal endoscopy included: a 3.2-mm flexible Machida ENT-III scope (Madrid, Spain), a Xenon Storz (Tuttlingen, Germany) light source, a Storz video monitor, an R170 Samsung (Seoul, Korea) DVD recorder, and a 4.7-GB DVD-R Maxprint (São Paulo, SP, Brazil) envelope. The images were recorded on $\mathrm{CDs}$ for further analysis and interpretation.

Functional swallowing tests were compared using the Boston Residue and Clearance Scale (BRACS), which has been validated by Kaneoca et $\mathrm{al}^{24}$ and is specially designed for studies involving FEES. The BRACS enables the functional analysis of residue considering three variables: volume, location, and patient response. Therefore, the analysis is based on the following criteria: 1) amount and location of the residue; 2) spontaneous clearing during swallowing; and 3 ) clearing effectiveness of swallowing. Based on this information, a total score is established. Two trained researchers compared the scores of volumes offered under the isolatedswallowing condition and under the dual-task condition. In cases in which there was disagreement, a third examiner performed the classification. The examiners were blinded to the patients and controls.

The BRACS is an 11-point ordinal scale that measures the severity of a residue problem. The scale specifically defines the amount of residue (none/coating; mild $=$ covering/filling $<1 / 3$ of the location; moderate $=$ covering/filling between $1 / 3$ and $2 / 3$ of the location; and severe $=$ covering/filling $>2 / 3$ of the location). The amount of residue is scored in 12 locations of the laryngopharynx. An extra point is added if residue is noted in four or more anatomical regions. An additional point is added if the residue is present inside the vestibule, placing the individual at the highest risk for aspiration after swallowing. If residue is observed and the individual demonstrates no spontaneous clearing swallows, an extra point is added to account for the apparent lack of pharyngeal sensation. Cued or spontaneous swallows are then judged for effectiveness (yes $=80 \%$ to $100 \%$ cleared; partially $=20 \%$ to $80 \%$ cleared; no $=0 \%$ to $20 \%$ cleared). ${ }^{24}$

\section{Experimental Procedures}

The participants were instructed as to the procedures at each stage of the examination: isolated swallowing; manual movement; and isolated swallowing and manual movement. After comprehending the tasks, the test began. Each task was interspersed by a rest period during the supply of food. The patients were instructed to stay at home and wait for the offer of new food. The offers of $3 \mathrm{~mL}$ and $5 \mathrm{~mL}$ of food were made in isolated-swallowing and dual-task sequences.

Swallowing: both groups underwent the FEES examination with $3 \mathrm{~mL}$ and $5 \mathrm{~mL}$ of moderately thick food classified according to the International Dysphagia Diet Standardiza- tion Initiative (IDDSI) as level $2^{25}$ in the syringe stained in blue, which is considered a safe consistency and volume for patients. The examination was performed by an ENT physician, and the food was offered by a speech therapist. The patient was positioned in a chair facing the ENT doctor and was asked to perform the previously practiced procedures.

Dual task: After the patient performed the procedures with the food being administered by the researcher, the protocol was repeated for IDDSI level 2 of fluid with the patient performing opposition of the thumb concurrently with swallowing, the dual-task condition. The hand movements used were opposition of the thumbs in sequence of $1-3-4-2$, in which the numbers correspond to: 1 - index finger; 2 - middle finger; 3 - ring finger; and 4 - pinkie. The order of presentation of the tasks was standardized for all patients.

\section{Analysis of the Results}

The statistical analysis was performed using the Statistical Package for the Social Sciences (SPSS, IBM Corp., Armonk, NY, US) software, version 20.0. For the comparisons of the association of single or dual tasks with the BRACS for each group, we applied the Mann-Whitney test. For the comparison of dual and single tasks and the $3 \mathrm{~mL}$ and $5 \mathrm{~mL}$ volumes for each group, we applied the Wilcoxon test. The paired $t$-test for independent samples was used for the statistical comparisons of means between the groups. For the intersection of data between the H\&Y, MoCA and MMSE variables, the Spearman correlation coefficient $\left(\mathrm{r}_{\mathrm{s}}\right)$ was used.

\section{Results}

The PD and HC groups consisted of 19 subjects with a mean age of 61.5 and 60.8 years respectively. Most of the subjects were men (68.4\%). The mean level of schooling was of 8 years for the PD group and of 10 years for the HC group, as shown in -Table 1.

The patients recruited were between H\&Y stages 1 and 4 . Of the 19 PD patients, 12 were classified as stage 2,6, as stage

Table 1 Demographic variables of the study sample

\begin{tabular}{|l|l|l|l|}
\hline Variables * & $\begin{array}{l}\text { Parkinson } \\
\text { disease } \\
\text { patients }\end{array}$ & $\begin{array}{l}\text { Healthy } \\
\text { controls }\end{array}$ & \multirow{2}{*}{-value } \\
\cline { 2 - 3 } & $\mathbf{( n = 1 9 )}$ & $\mathbf{( n = 1 9 )}$ & \\
\hline Age (years) & $61.5 \pm 7.1$ & $60.8 \pm 8.7$ & 0.792 \\
\hline Gender & & & 1,000 \\
\hline Male & $13(68.4)$ & $13(68.4)$ & \\
\hline Female & $6(31.6)$ & $6(31.6)$ & \\
\hline Schooling (years) & $8(5-11)$ & $10(6-15)$ & 0.191 \\
\hline $\begin{array}{l}\text { Mini Mental State } \\
\text { Examination }\end{array}$ & $24.6 \pm 4.9$ & $26.7 \pm 2.6$ & 0.120 \\
\hline $\begin{array}{l}\text { Montreal Cognitive } \\
\text { Assessment }\end{array}$ & $22.6 \pm 6.1$ & $21.8 \pm 4.5$ & 0.676 \\
\hline
\end{tabular}

Note: ${ }^{*}$ Data expressed as mean \pm standard deviation, median (25-75 percentile) or $\mathrm{n}(\%)$. 
Table 2 Comparison between the groups and tasks, and results of the Boston Residue and Clearance Scale for the 3$\mathrm{mL}$ and 5-mL volumes

\begin{tabular}{|c|l|l|l|}
\hline \multirow{2}{*}{ Variables } & $\begin{array}{l}\text { Parkinson } \\
\text { disease patients }\end{array}$ & $\begin{array}{l}\text { Healthy } \\
\text { controls }\end{array}$ & \multirow{2}{*}{-value* } \\
\cline { 2 - 3 } & $(\boldsymbol{n}=\mathbf{1 9 )}$ & \multicolumn{1}{|c|}{$(\boldsymbol{n}=\mathbf{1 9 )}$} & \\
\cline { 2 - 3 } & $\begin{array}{l}\text { Median } \\
(25-75 \%)\end{array}$ & $\begin{array}{l}\text { Median } \\
(25-75 \%)\end{array}$ & \\
\hline $3 \mathrm{~mL}$ & & $0(0-1)$ & $<0.001$ \\
\hline Single swallow & $2(1-2)$ & $0(01)$ & $<0.001$ \\
\hline Dual-task & $4(2-6)$ & 0.480 & \\
\hline$p$-value** & 0.014 & & \\
\hline 5 mL & & $0(0-1)$ & $<0.001$ \\
\hline Single swallow & $2(1-4)$ & $1(0-2)$ & $<0.001$ \\
\hline Dual-task & $4(2-6)$ & 0.366 & \\
\hline$p$-value** & 0.025 & & \\
\hline
\end{tabular}

Notes: ${ }^{*}$ Comparison between groups using the Mann-Whitney test; ${ }^{* *}$ comparison between tasks for each group using the Wilcoxon test.

3, and 1 , as stage 4. - Table 1 summarizes the demographic information of all participants.

The present study compared two conditions: isolated swallowing and swallowing under the dual-task condition with $3 \mathrm{~mL}$ and $5 \mathrm{~mL}$ of food. All participants performed the proposed tasks safely and successfully completed the evaluation. There was a statistically significant difference regarding the results of swallowing alone and of the dual task assessment between the two groups. The highest scores were found in the PD group for both tasks and volumes. The median score of the PD subjects for the 3-mL volume was 2 for swallowing and 4 for the dual task, while the median scores were significantly lower among the HC subjects. The same variation was observed for the $5-\mathrm{mL}$ volume, with a median score in the PD group of 2 for swallowing and 4 for the dual task, while the median score was 0 for swallowing and 1 for the dual task in the HC group, as shown in - Table 2 . When comparing the performance of the individual task versus the dual task for both groups and volumes, we observed that both the $3-\mathrm{mL}$ and $5-\mathrm{mL}$ volumes showed a statistically significant difference for the PD group, with no difference in the HC group. There was significant difference between scores for the 3-mL and 5-mL volumes for either task in the two groups (-Table 2 ).

-Table 3 evaluates the correlation between the BRACS score and the H\&Y, MoCA, and MMSE scores. No significant correlation was found between the BRACS scores and the degree of severity of PD as evaluated by the H\&Y, MMSE, MoCA, and DD scores (-Table $\mathbf{3}$ ).

-Fig. 1 shows a comparison of the variations in the BRACS, that is, the difference in the variation to describe differences between the dual-task and isolated-swallowing tests for each volume. There was greater variability in the results of the BRACS scores in the PD group when compared with the HC group. The differences were only significant for the $3-\mathrm{mL}$ volume $(p=0.012)$. For the $5-\mathrm{mL}$ volume, the difference was borderline $(p=0.053)$.

-Fig. 2 shows the correlation between the performance on the MoCA and the variation in the $3-\mathrm{mL}$ volume results. There was an inverse, significant association between the results of the MoCA with the change in BRACS scale between the dual task and isolated task only the in PD group $\left(r_{s}=-\right.$ $0.480 ; p=0.038$ ). The patients who had lower scores on the MoCA were those with greater variation in swallowing during the two tasks. In the control group, the association was not significant $\left(r_{s}=0.093 ; p=0.704\right)$. There was no significant correlation between variations in the BRACS score and other clinical variables $(p>0.05)$.

\section{Discussion}

When patients with PD simultaneously performed a motor task during swallowing, the swallowing parameters, as

Table 3 Correlations of variables with the Boston Residue and Clearance Scale by group using the Spearman correlation coefficient $\left(r_{\mathrm{s}}\right)$

\begin{tabular}{|c|c|c|c|c|c|c|}
\hline & \multicolumn{3}{|c|}{ Parkinson disease patients } & \multirow[b]{2}{*}{$\begin{array}{l}\text { Disease } \\
\text { Duration } \\
\text { (yr) }\end{array}$} & \multicolumn{2}{|c|}{ Healthy controls } \\
\hline & $\begin{array}{l}\text { Hoehn } \\
\text { \&Yahr } \\
\text { Scale }\end{array}$ & $\begin{array}{l}\text { Montreal } \\
\text { Cognitive } \\
\text { Assessment }\end{array}$ & $\begin{array}{l}\text { Mini Mental } \\
\text { State Examination }\end{array}$ & & $\begin{array}{l}\text { Montreal } \\
\text { Cognitive } \\
\text { Assessment }\end{array}$ & $\begin{array}{l}\text { Mini Mental } \\
\text { State Examination }\end{array}$ \\
\hline \multicolumn{7}{|l|}{$3 \mathrm{~mL}$} \\
\hline \multirow[t]{2}{*}{ Single task } & $r_{s}=0.029$ & $r_{s}=0.117$ & $r_{s}=0.090$ & $r_{s}=0.139$ & $r_{s}=-0.064$ & $r_{s}=0.013$ \\
\hline & $(p=0.908)$ & $(p=0.632)$ & $(p=0.715)$ & $(p=0.581)$ & $(p=0.796)$ & $(p=0.957)$ \\
\hline \multirow[t]{2}{*}{ Dual task } & $r_{s}=-0.208$ & $r_{s}=-0.369$ & $r_{s}=0.308$ & $r_{s}=-0.104$ & $r_{s}=0.057$ & $r_{s}=0.109$ \\
\hline & $(p=0.392)$ & $(p=0.120)$ & $(p=0.199)$ & $(p=0.681)$ & $(p=0.817)$ & $(p=0.658)$ \\
\hline \multicolumn{7}{|l|}{$5 \mathrm{~mL}$} \\
\hline \multirow[t]{2}{*}{ Single task } & $r_{s}=0.096$ & $r_{s}=-0.054$ & $r_{s}=0.033$ & $r_{s}=0.166$ & $r_{s}=-0.032$ & $r_{s}=0.039$ \\
\hline & $(p=0.695)$ & $(p=0.826)$ & $(p=0.892)$ & $(p=0.510)$ & $(p=0.896)$ & $(p=0.874)$ \\
\hline \multirow[t]{2}{*}{ Dual task } & $r_{s}=0.241$ & $r_{s}=-0.027$ & $r_{s}=0.230$ & $r_{s}=0.067$ & $r_{s}=-0.058$ & $r_{s}=-0.037$ \\
\hline & $(p=0.320)$ & $(p=0.913)$ & $(p=0.345)$ & $(p=0.792)$ & $(p=0.814)$ & $(p=0.882)$ \\
\hline
\end{tabular}




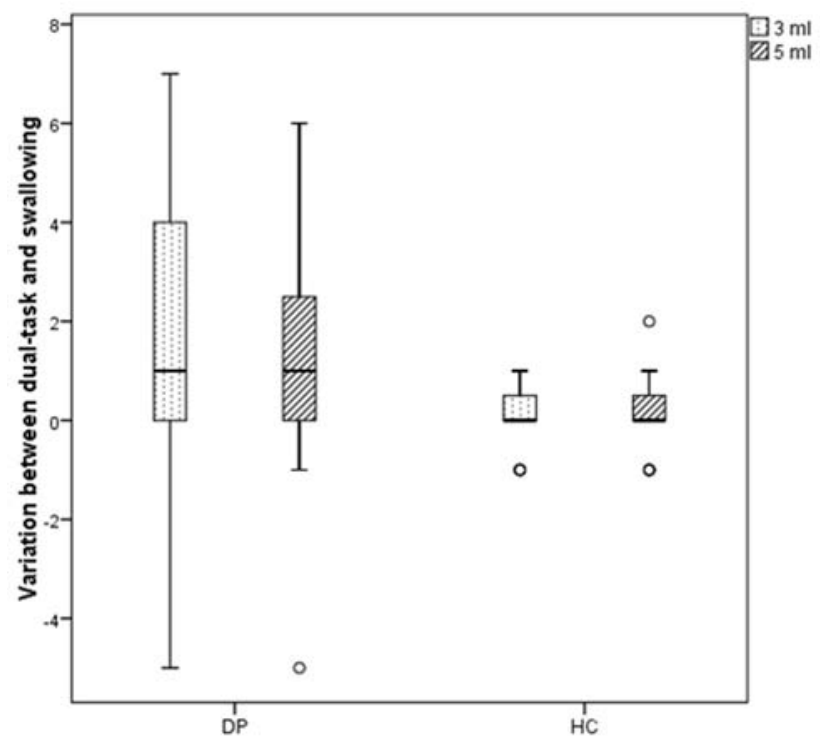

Fig. 1 Comparison of the results of variations of the BRACS for the dual task when compared with swallowing for each study group.

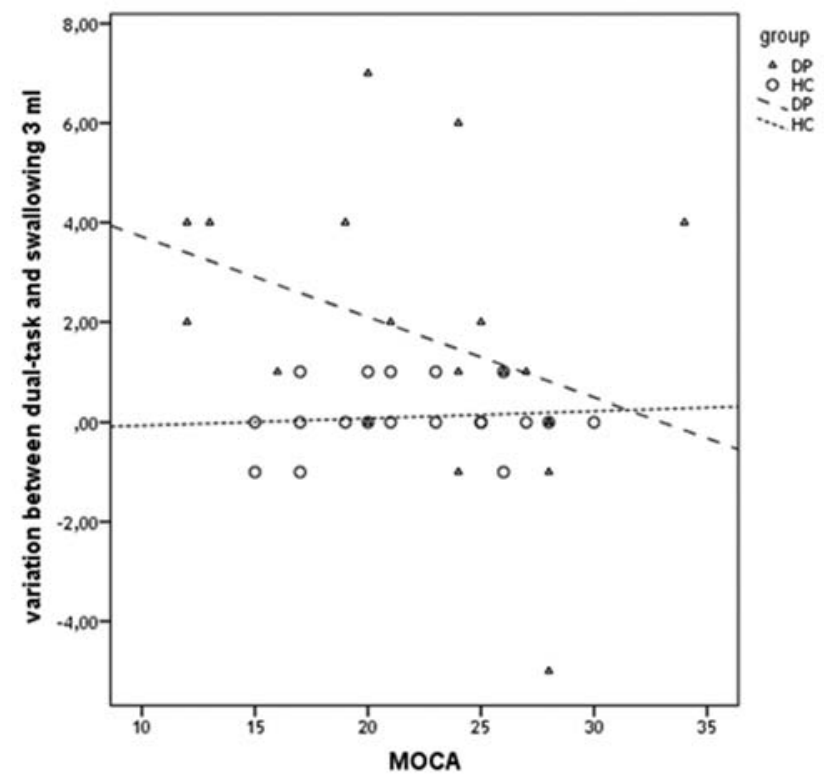

Fig. 2 Association between the differences in MoCA results and BRACS scores in the comparison of the 3-mL dual-task and isolatedswallowing tests.

assessed by the FEES, decreased for both the $3-\mathrm{mL}$ and $5-\mathrm{mL}$ swallow test, that is, motor activity became more important than swallowing, which caused an interference in the normal swallowing physiology. This interference was not observed in the control group.

The change in the swallowing symptom residue among PD patients reveals an effect on swallowing safety regarding the increased motor demand/cognitive ability required to conduct the motor task. These findings are consistent with those in the literature, indicating that motor tasks, such as walking, may be affected by external cognition competition or motor tasks. ${ }^{16}$

In a previous study, ${ }^{26}$ finger tapping and swallowing were used as a paradigm to compare the right and left hands during an intake of $300 \mathrm{~mL}$ of liquid barium, which was swallowed by healthy subjects and evaluated by videofluoroscopy. The aim of the study was to analyze the differences between the right and left hands to assess the lateralization of swallowing in the cortex by measuring the speed of manual movement. Finger tapping may set the pace by influencing the swallowing pattern. Despite methodological differences from our study, the task performance also changed in the dual-task condition with an increasing score, suggesting a higher demand for the combined task. A statistically significant increase in the BRACS score under the $3-\mathrm{mL}$ and $5-\mathrm{mL}$ volume conditions was evident in the PD group. There are no published studies using the FEES and motor tasks for comparison; however, the results of the study by Troche et $\mathrm{al}^{18}$ were consistent that swallowing is influenced by dual-task condition.

The FEES provides information about the anatomical and physiological patterns of residue problems. Visualization is concentrated toward the pharyngeal stage of swallowing; therefore, it is sensitive in detecting the amount of residue. ${ }^{22}$ The presence of residue in the laryngopharyngeal segment indicated significant results during dual-task swallowing, and was one of the main factors analyzed in the present study. This may contribute to decreased patient safety due to an increased risk of aspiration as a result of accumulation of secretions in different parts of the respiratory tract. Previous studies ${ }^{4,27}$ with PD patients demonstrated that residue in the valleculae or upper esophageal sphincter and fractionation of swallowing are associated with penetration/aspiration.

As shown in $\mathbf{- T a b l e ~} \mathbf{2}$, the present study demonstrated a statistically significant difference between the performance of the single task (isolated swallowing) and of the dual task (swallowing + manual movement), despite the lack of existing literature using the same functional paradigm for swallowing. In the study by Pinto et al, ${ }^{20}$ the competition between manual tasks and speech in PD patients resulted in a loss of the first task because of the second. For healthy adults, a combination of motor movements can be performed simultaneously, but this is not true for patients with PD.

The present study revealed that PD patients had impairments in cognitive function according to the MoCA and MMSE scores when compared with the HCs. Data from the BRACS showed that patients, even without any swallowing complaints, presented with impaired food safety as observed by the increase in the score. A limitation of the BRACS is the absence of a standard to determine a cut-off point for food safety. This was not the objective of the present work, but we were able to identify a variation in food safety in the dualtask test. Subsequent studies or meta-analysis data are needed to determine these standards for future analysis.

It has been observed that PD patients experience great difficulty with automatic movements beginning with the early stages of the disease, and these difficulties worsen when combined with other movements. These observations suggest that normal movement patterns are not lost, but are interrupted by competing motor and cognitive tasks. ${ }^{28}$ Swallowing can be considered a skill with conscious 
and automatic components directly related to each stage of the physiology. In the dual-task assessment, simultaneous motor movements caused dysfunction in swallowing physiology.

However, one limitation of the present study is the difficulty in establishing cut-off points for food safety with the BRACS. Second, both the volume and consistency of the bolus used were lower than the corresponding daily food consumption of the patients, which reduced the amount of residue found during the FESS assessment. This suggests that increasing the volume may involve safety risks, especially for patients with PD. Therefore, the volume and consistency were selected to determine the physiology of swallowing without compromising the safety of the testing.

The present study describes novel research regarding concurrent tasks on swallow physiology, but has limitations that should be considered when interpreting the results. The high variability in the sample may have limited the degree to which subtle changes could be statistically assessed. Replication of this study with a larger sample, comparing different stages, or a more homogeneous sample based on disease stage is necessary. Despite the aforementioned limitations, we believe that the elaborate experimental design of the study was appropriate for the dual-task design, to safe and efficient swallowing and FEES results.

The use of FEES for research is more recent than the video fluoroscopic swallowing exam. The FEES is now a gold standard to evaluate, and it is validated by the use of scales that enable diagnostic analysis of dysphagia as well as a comparative analysis. $^{14}$

The analysis of the cognitive performance of patients and controls via competitive tasks showed that there was an inverse correlation between the MoCA scores and the scores of the dual and individual tasks in the PD group, demonstrating that $\mathrm{PD}$ patients did not perform as well according to the MoCA, and that they had a decreased performance in the 3-mL volume test (-Fig. 2). This was not the case for the 5$\mathrm{mL}$ volume test, which can be attributed to a habituation and learning phenomenon following task presentation. The lack of correlation between the results of the cognitive tests is probably related to the nature of the tasks involved in the testing. The act of swallowing does not occur in isolation in daily life. However, limited information is available regarding interference of the external environment and concomitant motor tasks during swallowing. Distractions, such as cognitive and motor interference, can impair swallowing, which increases the complexity of the compensation reactions performed by the patients. However, situations that arise during evaluation and therapy occur in isolated and controlled environments with no external interference, which enables the patients to keep their focus on swallowing. Thus, this controlled environment may not reproduce the real situations of daily feeding conditions, which are worse than those found in the evaluation and therapy. Therefore, further studies are needed to understand the interference of motor and cognitive tasks in concomitant swallowing to elucidate the environmental changes that may occur routinely in patients with PD.

\section{Conclusion}

The participants in this PD study demonstrated worse swallowing safety in the dual-task versus single-task conditions. These data may reveal the inability of PD patients to coordinate the performance of concomitant tasks such as swallowing and manual movement.

This finding was not observed in the control group, which suggests the potential interference of motor and cognitive competition in dual-task functions.

Conflicts of Interest

The authors have none to disclose.

\section{References}

1 Lees AJ, Hardy J, Revesz T. Parkinson's disease. Lancet 2009;373 (9680):2055-2066

2 Hoehn MM, Yahr MD. Parkinsonism: onset, progression and mortality. Neurology 1967;17(05):427-442

3 Fernandes GC, Socal MP, Schuh AFS, Rieder CRM. Clinical and Epidemiological Factors Associated with Mortality in Parkinson's Disease in a Brazilian Cohort. Parkinsons Dis 2015;2015:959304. Doi: 10.1155/2015/959304

4 Argolo N, Sampaio M, Pinho P, Melo A, Nóbrega AC. Videofluoroscopic Predictors of Penetration-Aspiration in Parkinson's Disease Patients. Dysphagia 2015;30(06):751-758

5 Felix VN, Corrêa SMA, Soares RJ. A therapeutic maneuver for oropharyngeal dysphagia in patients with Parkinson's disease. Clinics (São Paulo) 2008;63(05):661-666

6 Malandraki GA, Perlman AL, Karampinos DC, Sutton BP. Reduced somatosensory activations in swallowing with age. Hum Brain Mapp 2011;32(05):730-743

7 Troche MS, Hubener I, Rosenbek JC, Okun MS, Sapienza CM. Respiratory- Swallowing Coordination and Swallowing Coordination and Swallowing Safety in Patients with Parkinson's Disease. Dysphagia 2011;26(03):218-224

8 Simons JA, Fietzek UM, Waldmann A, Warnecke T, Schuster T, Ceballos-Baumann AO. Development and validation of a new screening questionnaire for dysphagia in early stages of Parkinson's disease. Parkinsonism Relat Disord 2014;20(09):992-998

9 Simons JA. Swallowing Dysfunctions in Parkinson's Disease. Int Rev Neurobiol 2017;134:1207-1238

10 Sung HY, Park JW, Kim JS. The frequency and severity of gastrointestinal symptoms in patients with early Parkinson's disease. J Mov Disord 2014;7(01):7-12

11 Kalf JG, de Swart BJ, Bloem BR, Munneke M. Prevalence of oropharyngeal dysphagia in Parkinson's disease: a meta-analysis. Parkinsonism Relat Disord 2012;18(04):311-315

12 Pflug C, Bihler M, Emich K, et al. Critical Dysphagia is Common in Parkinson Disease and Occurs Even in Early Stages: A Prospective Cohort Study. Dysphagia 2018;33(01):41-50

13 Aviv JE. Prospective, randomized outcome study of endoscopy versus modified barium swallow in patients with dysphagia. Laryngoscope 2000;110(04):563-574

14 Tabaee A, Johnson PE, Gartner CJ, Kalwerisky K, Desloge RB, Stewart MG. Patient-controlled comparison of flexible endoscopic evaluation of swallowing with sensory testing (FEESST) and videofluoroscopy. Laryngoscope 2006;116(05):821-825

15 Lord S, Rochester L, Hetherington V, Allcock LM, Burn D. Executive dysfunction and attention contribute to gait interference in 'off' state Parkinson's Disease. Gait Posture 2010;31(02):169-174

16 Plotnik M, Dagan Y, Gurevich T, Giladi N, Hausdorff JM. Effects of cognitive function on gait and dual tasking abilities in patients with Parkinson's disease suffering from motor response fluctuations. Exp Brain Res 2011;208(02):169-179 
17 Wild LB, de Lima DB, Balardin JB, et al. Characterization of cognitive and motor performance during dual-tasking in healthy older adults and patients with Parkinson's disease. J Neurol 2013; 260(02):580-589

18 Troche MS, Okun MS, Rosenbek JC, Altmann LJ, Sapienza CM. Attentional resource allocation and swallowing safety in Parkinson's disease: a dual task study. Parkinsonism Relat Disord 2014; 20(04):439-443

19 Brodsky MB, Verdolini Abbott K, McNeil MR, Palmer CV, Grayhack JP, Martin-Harris B. Effects of divided attention on swallowing in persons with idiopathic Parkinson's disease. Dysphagia 2012;27 (03):390-400

20 Pinto S, Mancini L, Jahanshahi M, et al. Functional magnetic resonance imaging exploration of combined hand and speech movements in Parkinson's disease. Mov Disord 2011;26(12): 2212-2219

21 Zadikoff C, Fox SH, Tang-Wai DF, et al. A comparison of the mini mental state exam to the Montreal cognitive assessment in identifying cognitive deficits in Parkinson's disease. Mov Disord 2008;23(02):297-299
22 Dalrymple-Alford JC, MacAskill MR, Nakas CT, et al. The MoCA: well-suited screen for cognitive impairment in Parkinson disease. Neurology 2010;75(19):1717-1725

23 Langmore SE, Schatz K, Olsen N. Fiberoptic endoscopic examination of swallowing safety: a new procedure. Dysphagia 1988;2 (04):216-219

24 Kaneoka AS, Langmore SE, Krisciunas GP, et al. The Boston Residue and Clearance Scale: preliminary reliability and validity testing. Folia Phoniatr Logop 2013;65(06):312-317

25 Hanson B, Steele CM, Lam P, Cichero JAY. Fluid Testing Methods Recommended by IDDSI. Dysphagia 2018;•••;. Doi: 10.1007/ s00455-018-9957-9

26 Daniels SK, Corey DM, Fraychinaud A, DePolo A, Foundas AL. Swallowing lateralization: the effects of modified dual-task interference. Dysphagia 2006;21(01):21-27

27 Molfenter SM, Steele CM. The relationship between residue and aspiration on the subsequent swallow: an application of the normalized residue ratio scale. Dysphagia 2013;28(04):494-500

$28 \mathrm{Wu}$, Hallett M. A functional MRI study of automatic movements in patients with Parkinson's disease. Brain 2005;128(Pt 10):2250-2259 